\section{Ларина О.И.}

канд. экон. наук, ФГБОУ ВО «Государственный университет управления», г. Москва

e-mail: oilarina@mail.ru

\section{Larina 0.I.}

Candidate of Economic Sciences, State University of Management, Moscow

e-mail: oilarina@mail.ru

\section{Государственно-частное партнерство в сфере физической культуры и спорта}

\begin{abstract}
Аннотация
Доля расходов государства на создание и развитие инфраструктурных проектов в сфрере физической культуры и спорта, по многим экспертным оценкам, в настоящее время в России остается невысокой, и в условиях текущих кризисных явлений не покрывает существующей потребности. В этой связи остается открытым вопрос повышения эфффективности использования бюджетных средств и стимулирования притока частных инвестиций в обозначенную сферу. В статье проанализирована российская практика реализации государственно-частного партнерства в сфере фризической культуры и спорта. Исследованы формы государственночастного партнерства в обозначенной сфрере, тенденции развития и меры государственной поддержки, существующие как на общем фредеральном, так и на региональном уровнях. На основе анализа реализуемых проектов, а также правовых механизмов, обеспечивающих права инвесторов в Российской Федерации, сделаны выводы о необходимости совершенствования механизмов поддержки государственно-частного партнерства в сфере физической культуры и спорта, при этом целесообразно определить прозрачные и однозначные критерии выделения государственных средств. Основной целью статьи автор ставит обобщение и систематизацию применяемых механизмов государственной поддержки частных инвестиций в спортивной индустрии. Поскольку при реализации таких проектов необходимо учитывать специфику указанной сферы, исследованы современные тенденции в развитии предпринимательства в спортивной сфере. Сделан вывод, что при взаимодействии предпринимательства в сфере фризической культуры и спорта с государством должен достигаться баланс между частными интересами предпринимательства и социальными задачами, которые ставятся и должны решаться в интересах развития общества.
\end{abstract}

\section{Ключевые слова:}

реализация инсрраструктурных проектов, сфера физической культуры и спорта, государственно-частное партнерство, меры государственной поддержки государственно-частного партнерства, защита прав инвесторов, субсидирование процентной ставки.

\section{Public-private partnership in the sphere of physical culture and sports}

\begin{abstract}
According to many expert estimates, the share of state spending on the creation and development of infrastructure projects in the field of physical culture and sports in Russia remains low, and in the current crisis does not cover the existing needs. In this regard, the question of improving the efficiency of the use of budgetary funds and stimulating the flow of private investment in this area remains open. The article analyzes the Russian practice of public-private partnership in the field of physical culture and sports. The forms of public-private partnership in the designated area, development trends and measures of state support existing both at the Federal and regional levels are investigated. Based on the analysis of the ongoing projects, as well as legal mechanisms that ensure the rights of investors in the Russian Federation, conclusions are drawn on the need to improve the mechanisms of support for public-private partnership in the field of physical culture and sports, while it is advisable to determine transparent and unambiguous criteria for the allocation of public funds. The main purpose of the article is to generalize and systematize the mechanisms of state support of private investment in the sports industry. Since the implementation of such projects should take into account the specifics of this area, the current trends in the development of entrepreneurship in the sports sector. It was concluded that the interaction of business in the field of physical culture and sports with the state should achieve a balance between the private interests of business and social objectives that are set and should be addressed in the interests of society.
\end{abstract}

\section{Keywords:}

implementation of infrastructure projects, sphere of physical culture and sports, public-private partnership, measures of state support of public-private partnership, protection of investor's rights, subsidized interest rate.

(c) The Author(s), 2018 This is an open access article under the CC BY 4.0 license (http://creativecommons.org/licenses/by/4.0/) 
Во многих странах спорт является областью общественных отношений, где активно применяются и динамично развиваются проекты государственно-частного партнерства. Государственночастное партнерство (далее - ГЧП) представляет собой взаимодействие государства и частного бизнеса, что часто используется в развитии общественной инфраструктуры. В то же время как расходы, так и выгоды, получаемые от сотрудничества государства и частного бизнеса, детали финансирования и эксплуатации спортивных сооружений, должны систематически исследоваться и анализироваться соответствующими органами государственной власти. В настоящее время дополняется и совершенствуется механизм государственной поддержки частных инвестиций в спортивную сферу. Партнерство государства и бизнеса, правильно управляемое и грамотно регламентируемое, может быть высоко эффективным механизмом. Однако, как отмечают специалисты, многие проекты ГЧП давали неоднозначные результаты в плане оправдания ожиданий, главным образом по причине их ненадлежащей организации, а также потому, что в некоторых случаях договорные обязательства основывались на некорректном или прямо ошибочном анализе ожидаемых затрат и доходов [9].

Так, в 2017 г. в Российской Федерации (далее РФ) количество спортивных сооружений на 100 тыс. человек населения в среднем составляло 214 ед., при этом самая высокая обеспеченность наблюдается в Тамбовской и Белгородской областях - 401 и 400 ед. соответственно, а самый низкий показатель в Чеченской республике - 100 ед. Общее количество спортивных сооружений в РФ в 2017 г. составляло 305288 единиц, при этом количество стадионов 1729 ; плоскостных сооружений (игровые площадки, поля, беговые дорожки) - 147 472; залов - 72 669; бассейнов - 5654 (см. табл. 1) [14].

Следует отметить, что данный показатель (количество спортивных сооружений на 100 тыс. человек) входит в состав показателей оценки эффективности деятельности исполнительных органов местной власти. Однако, на наш взгляд, прямой взаимосвязи, например, с численностью спортсменов субъекта РФ, включенных в список кандидатов в спортивные сборные команды РФ (другой целевой показатель), не наблюдается. Так, в указанных выше субъектах РФ количество спортсменов, включенных в список кандидатов в спортивные сборные команды РФ, составляет в Тамбовской и Белгородской областях - 37 и 73 чел. соответственно, а в Чеченской республике - 44 чел. Лидерами по обозначенному показателю являются: г. Москва - 1530 чел. и г. СанктПетербург - 616 чел., а аутсайдер - Чукотский автономный округ - 0 чел. При этом количество спортивных сооружений на 100 тыс. чел. населения в г. Москве составляет 175 ед., в г. Санкт-Петербург - 147 ед., а в Чукотском автономном округе 218 ед. По мнению автора, показателем, в большей степени влияющим на количество спортсменов, включенных в список кандидатов в спортивные сборные команды РФ, является показатель наличия необходимых кадров.

Таблица 1

Количество спортивных сооружений, а также обеспеченность кадрами в Российской Федерации и в некоторых субъектах Российской Федерации в 2017 г.

\begin{tabular}{|c|c|c|c|c|c|c|}
\hline \multirow{2}{*}{ Субъект РФ } & \multicolumn{5}{|c|}{ Спортивные сооружения } & \multirow{2}{*}{ Кадры } \\
\hline & Всего & Стадионы & $\begin{array}{c}\text { Плоскостные } \\
\text { спортивные сооружения }\end{array}$ & Залы & Бассейны & \\
\hline Белгородская область & 5791 & 23 & 3219 & 821 & 145 & 4181 \\
\hline Тамбовская область & 4187 & 21 & 2844 & 639 & 41 & 2200 \\
\hline г. Москва & 20844 & 21 & 11434 & 3684 & 379 & 36720 \\
\hline г. Санкт-Петербург & 7479 & 8 & 2821 & 1845 & 312 & 19333 \\
\hline Чеченская республика & 1408 & 13 & 745 & 497 & 10 & 5224 \\
\hline Чукотский автономный округ & 91 & 0 & 8 & 54 & 6 & 183 \\
\hline Российская Федерация & 305288 & 1729 & 147472 & 72669 & 5654 & 375369 \\
\hline
\end{tabular}

Источник: [14] 
По данным Национального центра ГЧП (Платформа поддержки инфраструктурных проектов), на начало июля 2018 г. в базе социальных проектов (раздел физическая культура и спорт) было зарегистрировано 90 проектов [15]. Из них формы реализации зарегистрированы следующие: 50 ед. в форме концессионного соглашения; 25 ед. в форме договора аренды с инвестиционными обязательствами; 12 ед. - в форме муниципального СГЧП; - 3 ед. - в форме регионального СГЧП [15]. Другие формы реализации проектов не востребованы в этой сфере (проекты отсутствуют). Таким образом, основные формы реализации инфраструктурных проектов в области физической культуры и спорта и их сравнительные характеристики представлены в табл. 2.

Исходя из представленных выше зарегистрированных сведений о реализуемых проектах в спорте, самой распространенной юридической моделью для реализации инфраструктурных проектов в области физической культуры и спорта является концессионное соглашение (заключаемое в соответствии с Федеральным законом № 115). Можно заметить (см. табл. 2), что нередко источниками финансирования при реализации инфраструктурных проектов в области физической культуры и спорта выступают государственные субсидии. Тем не менее, вопрос интенсификации привлечения частных инвестиций в сферу физкультуры и спорта остается достаточно актуальным. Возникает вопрос о препятствиях, которые тормозят развитие обозначенной сферы. Отмечаются, например, следующие проблемы: в связи с санкциями наблюдается отток иностранного капитала, найти инвесторов для новых проектов на внутреннем рынке становится сложнее из-за избирательного подхода к финансированию. Кроме того, «незавершенность» законодательной базы, регламентирующей проектное финансирование, периодическая доработка законов и разработка подзаконных актов, а также регулярное изменение «правил игры» также существенно снижают активность инвесторов [11].

Так, все реализуемые проекты оцениваются инвесторами с позиции рискованности, в оценку которой закладывается и влияние указанных выше факторов. Если анализировать рискованность проектов ГЧП в России, то следует отметить, что ГЧП является механизмом привлечения частных инвестиций в создание объектов общественной инфраструктуры или обеспечения эффективного управления имуществом, находящимся в государственной или муниципальной собственности. Поскольку в данном случае одной из сторон выступает публичный партнер (РФ; субъект РФ; муниципальное образование), то, как правило, основным ориентиром для инвестора (особенно зарубежного) становится кредитный рейтинг публичного партнера (или его облигационного выпуска). По состоянию на начало 2018 г. только 46 субъектов и муниципалитетов РФ имели рейтинг, присвоенный кредитными рейтинговыми агентствами, и лишь 5 из них имели высший рейтинг по национальной шкале (Москва, Санкт-Петербург, Тюменская область, Ханты-Мансийский автономный округ - Югра, Ямало-Ненецкий автономный округ) [7].

Так, наличие и значение рейтинга является первым ориентиром для инвестора при анализе рисков и возможности участия в финансировании каких-либо проектов, так представляет собой комплексную независимую оценку рискованности инвестиций. Вторым важным ориентиром для инвестора будет емкая и содержательная правовая база, регламентирующая предпринимательскую деятельность, в которой четко закреплены права и обязанности сторон. Российскую правовую базу, регулирующую взаимоотношения между государством и инвестором, можно представить в виде иерархичной структуры, то есть уровни, располагающиеся ниже по отношению к другим уровням, являются главенствующими. Так, базовые гарантии реализации инвестиционной деятельности, а также права на предпринимательскую деятельность и собственность отражаются в Конституции РФ. Следующий уровень: нормы, заложенные Бюджетным кодексом РФ, в соответствии с которым если международным договором России установлены иные правила, чем те, которые предусмотрены бюджетным законодательством РФ, применяются правила международного договора (см. ст. 4). Уровень федерального законодательства также включает Гражданский кодексе РФ, где отражаются вопросы заключения договоров, в которых одной из сторон может выступать инвестор. Современный блок федерального законодательства, обеспечивающий гарантии прав инвесторов, включает: Федеральный закон от 09.07.1999 № 160-Ф3 «Об иностранных инвестициях в Российской Федерации»; Федеральный закон от 25.02.1999 № 39-Ф3 «Об инвестиционной деятельности в Российской Федерации, осуществляемой в форме капитальных вложений»; Федеральный закон от 05.03.1999 № 46-Ф3 «О защите прав и законных интересов инвесторов на рынке ценных бумаг» $[2 ; 3 ; 4]$. 
Анализ форм реализации инфраструктурных проектов в области физической культуры и спорта

\begin{tabular}{|c|c|}
\hline A & Аренда с инвестиционными условиями \\
\hline 1 & Объект соглашения - любые объекты \\
\hline 2 & Право собственности на объект - государственная (муниципальная) собственность \\
\hline 3 & Предоставление земельных участков и объекта - объект или земельный участок передаются на правах аренды \\
\hline 4 & Источник возврата инвестиций частного партнера - доход от эксплуатации \\
\hline 5 & Бюджетное финансирование частного партнера по соглашению - нет \\
\hline 6 & Источник финансирования платежей по соглашению - нет \\
\hline Б & Концессионное соглашение с прямым сбором платы \\
\hline 1 & Объект соглашения - объекты, определенные в Законе № 115, в том числе объекты спорта \\
\hline 2 & Право собственности на объект - государственная (муниципальная) собственность концедента \\
\hline 3 & $\begin{array}{l}\text { Предоставление земельных участков и объекта - предоставление земельных участков и объекта - объект передается } \\
\text { на правах владения и пользования концессионеру земельные участки передаются по договору аренды (субаренды) } \\
\text { (дополнительных торгов не требуется) }\end{array}$ \\
\hline 4 & Источник возврата инвестиций частного партнера - доход от сбора платы с пользователей \\
\hline 5 & Бюджетное финансирование частного партнера по соглашению - капитальный грант \\
\hline 6 & Источник финансирования платежей по соглашению - бюджетные инвестиции на капитальный грант \\
\hline B & Концессионное соглашение с прямым сбором платы и гарантией минимального дохода \\
\hline 1 & Объект соглашения - объекты, определенные в Законе №115, в том числе объекты спорта \\
\hline 2 & Право собственности на объект - государственная (муниципальная) собственность концедента \\
\hline 3 & $\begin{array}{l}\text { Предоставление земельных участков и объекта - предоставление земельных участков и объекта - объект передается } \\
\text { на правах владения и пользования концессионеру земельные участки передаются по договору аренды (субаренды) } \\
\text { (дополнительных торгов не требуется) }\end{array}$ \\
\hline 4 & $\begin{array}{l}\text { Источник возврата инвестиций частного партнера - доход от сбора платы с пользователей и гарантия минимального дохода } \\
\text { из бюджета }\end{array}$ \\
\hline 5 & Бюджетное финансирование частного партнера по соглашению - капитальный грант, гарантия минимального дохода (ГмД) \\
\hline 6 & Источник финансирования платежей по соглашению - бюджетные инвестиции на капитальный грант, субсидии на ГМД \\
\hline$\Gamma$ & Концессионное соглашение с платой концедента \\
\hline 1 & Объект соглашения - объекты, определенные в Законе № 115, в том числе объекты спорта \\
\hline 2 & Право собственности на объект - государственная (муниципальная) собственность концедента \\
\hline 3 & $\begin{array}{l}\text { Предоставление земельных участков и объекта - предоставление земельных участков и объекта - объект передается } \\
\text { на правах владения и пользования концессионеру земельные участки передаются по договору аренды (субаренды) } \\
\text { (дополнительных торгов не требуется) }\end{array}$ \\
\hline 4 & Источник возврата инвестиций частного партнера - плата концедента из бюджета \\
\hline 5 & $\begin{array}{l}\text { Бюджетное финансирование частного партнера по соглашению - капитальный грант, плата концедента, включающая } \\
\text { инвестиционную составляющую }\end{array}$ \\
\hline 6 & $\begin{array}{l}\text { Источник финансирования платежей по соглашению - бюджетные инвестиции на капитальный грант, субсидии на плату } \\
\text { концедента }\end{array}$ \\
\hline Д & Соглашение о государственно-частном партнерстве \\
\hline 1 & Объект соглашения - объекты, определенные в Законе о ГЧП, которые могут находиться в частной собственности \\
\hline 2 & $\begin{array}{l}\text { Право собственности на объект - частная собственность (собственность частного партнера) / государственная собствен- } \\
\text { ность, если преимущественно бюджетное финансирование }\end{array}$ \\
\hline 3 & $\begin{array}{l}\text { Предоставление земельных участков и объекта - предоставление земельных участков и объекта - объект передается } \\
\text { на правах владения и пользования, после ввода в эксплуатацию возникает право собственности частного партнера на } \\
\text { объект. Земельные участки передаются по договору аренды (субаренды) (дополнительных торгов не требуется) }\end{array}$ \\
\hline 4 & $\begin{array}{l}\text { Источник возврата инвестиций частного партнера - доход от эксплуатации и/или технического обслуживания объекта } \\
\text { выплаты публичного партнера }\end{array}$ \\
\hline 5 & $\begin{array}{l}\text { Бюджетное финансирование частного партнера по соглашению - частичное фринансирование создания объекта, полное или } \\
\text { частичное финансирование эксплуатации и/или технического обслуживания объекта }\end{array}$ \\
\hline 6 & Источник фринансирования платежей по соглашению - субсидии \\
\hline
\end{tabular}

*Закон № 115 - Федеральный закон «О концессионных соглашениях» от 21.07.2005 г. № 115-ФЗ РФ

Источник: [13; 6] 
Регулирование инвестиционной деятельности не ограничивается указанными актами. Так, в случае изменения макроэкономических условий или законодательства, напрямую затрагивающих проект (налоги, льготы т. д.), вносятся обоснованные изменения в соглашение в части объема софинансирования государственной публичной стороной проекта и сроков его реализации [5]. Также в исследуемой сфере одним из уровней нормативного регулирования является региональный уровень, где могут быть собственные механизмы реализации поддержки инвестиционной деятельности (анализ представлен далее).

Как отмечалось выше, в правовом механизме обеспечения гарантий соблюдения прав инвесторов целесообразно выделять несколько групп вопросов, в том числе вопросы предоставления льгот инвесторам. Можно отметить наличие в РФ налоговых и неналоговых льгот, применяемых при частных инвестициях в экономику.

Предусмотрена льготная ставка по налогу на имущество на период действия концессионного или ГЧП соглашения создаваемого по такому концессионному или ГЧП соглашению; льготная ставка по налогу на прибыль концессионера (частного партнера) при вводе объекта в эксплуатацию в рамках ставки подлежащей зачислению в бюджет субъекта; льготная ставка по транспортному налогу [1].

Кроме того, в РФ предусмотрены также неналоговые льготы и механизмы поддержки государством частных инвесторов: льготное или безвозмездное подключение к коммунальным сетям; субсидирование процентной ставки по займам; методическое и организационное содействие [18].

Если анализировать инвестиционную поддержку государством сферы физической культуры и спорта, то можно отметить развитие комплексного подхода со стороны государства в отношении возможных мер, способных привлечь частный капитал в данную сферу. Такие обобщенные меры государственной поддержки инвестиционной деятельности в сфере физической культуры и спорта следующие $[1 ; 13 ; 18]$.

1. Услуги, оказываемые населению по организации и проведению физкультурных, физкультурнооздоровительных и спортивных мероприятий на территории фитнес-центра как индивидуально, так и под руководством тренера, освобождаются от налогообложения налогом на добавленную стоимость. Данное право установлено Налоговым кодексом РФ на общем федеральном уровне.

2. Применение льготной налоговой ставки по налогу на прибыль организаций, ведущих деятельность в области физической культуры и спорта. Данное право установлено и может применяться по решению регионального законодателя.

3. Освобождение от уплаты налога на имущество организаций, созданного и (или) приобретенного, а также введенного в эксплуатацию в рамках реализации инвестиционных проектов имущества. Данное право установлено и может применяться по решению регионального законодателя.

4. Инвестиционный налоговый кредит - изменение срока уплаты налога, при котором организации (которая оказывает особо важные услуги населению) предоставляется возможность в течение определенного срока и в определенных пределах уменьшать свои платежи по налогу с последующей поэтапной уплатой суммы кредита и начисленных процентов. Данное право установлено Налоговым кодексом РФ на общем федеральном уровне, при этом должен быть Закон регионального уровня, устанавливающий критерии «оказание особо важных услуг населению».

5. Льготная ставка арендной платы в отношении государственного имущества. Данное право установлено и может применяться по решению регионального законодателя.

6. Государственные гарантии в пределах общей суммы предоставляемых гарантий, указанной в законе субъекта РФ о бюджете на очередной финансовый год для юридических лиц, реализующие инвестиционные проекты в сфере физической культуры и спорта. Данное право установлено и может применяться по решению регионального законодателя.

7. Предоставление в залог объектов государственной собственности для юридических лиц, реализующие социально значимые инвестиционные проекты в сфере физической культуры и спорта. Данное право установлено и может применяться по решению регионального законодателя.

8. Договор аренды земельного участка без проведения торгов в случае предоставления земельного участка в целях реализации масштабных инвестиционных проектов, объектов социально-культурного и коммунально-бытового назначения. Данное право установлено и может применяться по решению регионального законодателя.

При этом отметим, что в настоящее время Министерство спорта РФ развивает возможные механизмы поддержки инвестиционных проектов в сфере физической культуры и спорта. Так, например, планируется применение предоставления субсидий на софинансирование затрат на создание и эксплуатацию объектов для субъектов, осуществляющих инвестиционную деятельность в сфере физической 
культуры и спорта, а также предоставление субсидий на софинансирование затрат на создание инженерных сетей для субъектов, осуществляющих инвестиционную деятельность в сфере физической культуры и спорта. Такой механизм доведения субсидии из федерального бюджета через бюджет субъекта РФ до частного партнера уже был реализован в 2018 г. Получателей этой субсидии пока двое: Воронежская и Новосибирская области. Общая сумма субсидий в 2018 г. составит 150 млн руб. [16]. В то же время открытого и ясного порядка поддержки инвестиционных проектов в сфере физической культуры и спорта пока нет.

Например, в рамках механизма, действующего в отношении промышленных объектов, уже определен порядок предоставления субсидий из федерального бюджета на компенсацию части затрат на уплату процентов по кредитам, полученным в российских организациях в 2017-2019 гг., и на уплату части купонного дохода по облигациям, выпущенным в 2017-2019 гг., для целей реализации инвестиционного проекта. Такие средства должны быть использованы на реализацию новых комплексных инвестиционных проектов. Субсидии предоставляются при условии внесения инвестиционного проекта в перечень комплексных инвестиционных проектов по приоритетным направлениям гражданской промышленности Министерства промышленности и торговли РФ. Основные условия такого субсидирования: кредит от 3 лет; стоимость проекта от 150 млн руб. до 7,5 млрд руб.; кредитные средства могут быть не более $80 \%$ стоимости проекта (ограничение не распространяется на проекты, привлекавшие средства с помощью выпуска облигаций); размер и сроки поддержки: если процентная ставка выше базового индикатора - возмещается $70 \%$ базового индикатора, если процентная ставка ниже базового индикатора - возмещается $70 \%$ от процентной ставки. Выплата субсидии происходит 2 раза в год (во II и IV кварталах).

Кроме указанного механизма, по информации Министерства спорта России, организовано взаимодействие с государственными банками: ПАО «Сбербанк России», ПАО «Банк ВТБ», АО «Россельхозбанк». Указанные банки стали организаторами конкурса «Ежегодная общественная премия «Регионы - устойчивое развитие», в рамках которого инвестиционный проект может получить целевой возвратный заем на льготных условиях. Попечительским советом конкурса сформирован список из 327 победителей, из них 35 проектов в сфере спорта. Эти проекты получили льготную поддержку в течение нескольких лет на общую сумму 20,4 млрд рублей [16]. Таким образом, в настоящее время государством прорабатываются и развиваются новые механизмы поддержки отрасли физической культуры и спорта.

В заключение отметим, что для заинтересованности инвесторов целесообразно сформировать четкий и обоснованный механизм предоставления субсидированных кредитов проектам ГЧП, в котором были бы однозначно прописаны критерии программы по субсидированию процентных ставок. Другой существенной проблемой, тормозящей развитие отрасли физической культуры и спорта, следует назвать низкую коммерческую привлекательность этой отрасли, а также высокие административные барьеры [12]. В РФ доля предпринимательской деятельности в сфере физической культуры и спорта по размеру оборота оказанных услуг в общем объеме платных услуг населению по состоянию на май 2018 г. составляет 0,7\% (5,6 млрд руб. из 759,7 млрд. руб.). В январе-апреле 2018 г. доля убыточных организаций, осуществляющих деятельность в области спорта, отдыха и развлечений, составила $39 \%$, а доля прибыльных - 61 \%. В то же время общее финансовое положение данной сферы является убыточным (сальдо составило: -4,5 млрд руб.), в том числе убыток составил 7,2 млрд руб., а прибыль - 2,7 млрд руб. [19]. Таким образом, текущая ситуация в сфере предпринимательства в физической культуре и спорте достаточно сложная: хотя основная масса организаций прибыльна, убыток в отрасли превалирует в связи с тем, самые крупные организации убыточны. Также имеется тенденция уменьшения количества организаций, в то время как объем спортивного рынка в мире, включая индустрию спортивного оснащения и оборудования, на начало XXI века составлял в отдельных странах $2 \%$ от валового внутреннего продукта [10].

Нужно согласиться с точкой зрения, что для развития предпринимательской деятельности в сфере физической культуры и спорта необходимо совершенствовать нормативно-правовую базу, сделать прозрачными земельные отношения для реализации долгосрочных инвестиционных проектов, стимулировать покупательский спрос и заинтересованность индивидуальных потребителей индустрии спорта, развивать предпринимательские традиции в этой сфере [8].

При взаимодействии предпринимательства в сфере физической культуры и спорта с государством должен достигаться баланс между частными интересами предпринимательства и социальными задачами, которые ставятся и должны решаться в интересах развития общества. Такими социальными задачами являются: повышение доли граждан РФ, занимающихся 
спортом, уровеня обеспеченности населения спортивными сооружениями; доли российских спортсменов, ставших призерами игр Олимпиад; успешная подготовка и проведение международных спортивных соревнований; вхождение сборной команды России в тройку призеров; количество созданных рабочих мест в спортивных организациях [17]. Организуя мониторинг субъектов предпринимательства в сфере физической культуры и спорта для анализа эффективности их взаимодействия с государством, следует учитывать, что такой мониторинг должен быть организован государственными органами без внедрения дополнительной административной нагрузки на предпринимательство, поскольку, как отмечалось выше, текущая финансовая ситуация в данной сфере достаточно сложная.

\section{Библиограффический список}

1. Налоговый кодекс РФ (ред. от 27.11.2018 г. № 424-Ф3) [Электронный ресурс]. - Режим доступа: Справочная правовая система «КонсультантПлюс» http://www. consultant.ru/cons (дата обращения: 10.09.2018).

2. Федеральный закон «Об иностранных инвестициях в Российской Федерации» от 09.07.1999 г. № 160-Ф3 (ред. от 31.05.2018 г. № 122-Ф3) [Электронный ресурс]. - Режим доступа: Справочная правовая система «КонсультантПлюс» http://www.consultant.ru/cons (дата обращения: 10.09.2018).

3. Федеральный закон «Об инвестиционной деятельности в Российской Федерации, осуществляемой в форме капитальных вложений» от 25.02.1999 г. № 39-Ф3 (ред. от 26.07.2017 г. № 205-Ф3) [Электронный ресурс]. Режим доступа: Справочная правовая система «КонсультантПлюс» http://www.consultant.ru/cons (дата обращения: 10.09.2018).

4. Федеральный закон «О защите прав и законных интересов инвесторов на рынке ценных бумаг» от 05.03.1999 г. № 46-Ф3 (ред. От 19.12.2006 № 238-Ф3) [Электронный ресурс]. - Режим доступа: Справочная правовая система «КонсультантПлюс» http://www. consultant.ru/cons (дата обращения: 10.09.2018).

5. Федеральный закон «О государственно-частном партнерстве, муниципально-частном партнерстве в Российской Федерации и внесении изменений в отдельные законодательные акты Российской Федерации» от 3.07.2015 г. № 224-Ф3 (ред. от 29.07.2018 г. № 261-Ф3) [Электронный ресурс]. - Режим доступа: Справочная правовая система «КонсультантПлюс» http://www. consultant.ru/ http://www.consultant.ru/cons (дата обращения: 10.09.2018).

6. Федеральный закон «О концессионных соглашениях» от 21.07.2005 г. № 115-Ф3 (ред. от 03.08.2018 № 312-Ф3) [Электронный ресурс]. - Режим доступа: Справочная правовая система «КонсультантПлюс» http://www. consultant.ru/ http://www.consultant.ru/cons (дата обращения: 10.09.2018).

7. Ларина, О. И. Деятельность рейтинговых агентств в РФ и их влияние на субфедеральные заимствования / О. И. Ларина, Н. В. Морыженкова // Управление. 2017 г. - № 4 (18). - С. 22-28.

8. Маслов, А. В. Концептуальные подходы к разработке стратегии предпринимательской деятельности в сфере физической культуры и спорта / Автореф. диссертации канд. экон. наук. - Екатеринбург, 2013. - 24 с.

9. Сазанов, В. Е. Государственно-частное партнерство. Гражданско-правовые, административно- правовые

\section{References}

1. Nalogovyi kodeks RF (red. ot 27.11.2018 g. № 424-FZ) [The tax code of the Russian Federation (in ver. 27.11.2018 № 424$F Z$ )]. Available at: Spravochnaya pravovaya sistema «Konsul'tantPlyus» http://www.consultant.ru/cons (accessed 10.09.2018).

2. Federal'nyi zakon «Ob inostrannykh investitsiyakh v Rossiiskoi Federatsii» ot 09.07.1999 g. № 160-FZ (red. ot 31.05.2018 g. № 122-FZ) [Federal law «On foreign investments in the Russian Federation» (in ver. 31.05.2018 № 122-FZ)]. Available at: Spravochnaya pravovaya sistema «Konsul'tantPlyus» http:// www.consultant.ru/cons (accessed 10.09.2018).

3. Federal'nyi zakon «Ob investitsionnoi deyatel'nosti v Rossiiskoi Federatsii, osushchestvlyaemoi v forme kapital'nykh vlozhenii» ot 25.02.1999 g. № 39-FZ (red. ot 26.07.2017 g. № 205-FZ) [Federal law «On investment activities in the Russian Federation in the form of capital investments» (in ver. 26.07.2017№ 205-FZ)]. Available at: Spravochnaya pravovaya sistema «Konsul'tantPlyus» http://www.consultant.ru/ cons (accessed 10.09.2018).

4. Federal'nyi zakon «O zashchite prav i zakonnykh interesov investorov na rynke tsennykh bumag» ot $05.03 .1999 \mathrm{~g}$. № 46FZ (red. ot 19.12.2006 № 238-FZ) [Federal law «On protection of the rights and legitimate interests of investors in the securities market» (in ver. 19.12.2006 № 238-FZ)]. Available at: Spravochnaya pravovaya sistema «Konsul'tantPlyus» http://www.consultant.ru/cons (accessed 10.09.2018).

5. Federal'nyi zakon «O gosudarstvenno-chastnom partnerstve, munitsipal'no-chastnom partnerstve v Rossiiskoi Federatsii i vnesenii izmenenii v otdel'nye zakonodatel'nye akty Rossiiskoi Federatsii» ot 13.07.2015 g. № 224-FZ (red. ot 29.07.2018 g. № 261-FZ) [Federal law «On public-private partnership, municipal-private partnership in the Russian Federation and amendments to certain legislative acts of the Russian Federation» (in ver. 29.07.2018 № 261-FZ)]. Available at: Spravochnaya pravovaya sistema «Konsul'tantPlyus» http://www.consultant.ru/cons (accessed 10.09.2018).

6. Federal'nyi zakon «O kontsessionnykh soglasheniyakh» ot 21.07.2005 g. № 115-FZ (red. ot 03.08.2018 № 312-FZ) [Federal law «On concession agreements» (in ver. 03.08.2018 № 312-FZ)]. Available at: Spravochnaya pravovaya sistema «Konsul'tantPlyus» http://www.consultant.ru/cons (accessed 10.09.2018).

7. Larina O. I., Moryzhenkova N. V. Deyatel'nost' reitingovykh agentstv v RF i ikh vliyanie na subfederal'nye zaimstvovaniya [The activities of rating agencies in Russia and their impact on sub-national borrowing]. Upravlenie, 2017, I. 4 (18), pp. 22-28.

8. Maslov A. V. Kontseptual'nye podkhody k razrabotke strategii predprinimatel'skoi deyatel'nosti v sfere fizicheskoi 
и финансово-правовые аспекты. Монография. ООО «Буки Веди», 2012. - 492 с.

10. Селиваненко, А. Е. Предпринимательская деятельность в сфере физической культуры и спорта и механизм ее развития в рыночных условиях хозяйствования. Автореф. диссертации канд. экон. наук. - Москва, 2003. -24 c.

11. Сильвестров, С. Н. и др. Модели финансирования естественных монополий: бюджетное, корпоративное и проектное финансирование / С. Н. Сильвестров, Н. В. Кузнецов, Г. Л. Подвойский, Н. Е. Котова // Финансы: теория и практика. - 2017. - № 5. - С. 22-29.

12. Заседание рабочей группы по вопросу развития ГЧП в фере физической культуры и спорта, созданной по инициативе вице-премьера А. Дворковича (от 29.07.2016). [Электронный ресурс]. - Режим доступа: http://pppcenter.ru/29/novosti/pppcenter-news/ investoram-v-proektax-gchp-v-sporte-trebuetsyagarantiya-vozvratnosti-investiczij.html (дата обращения: 10.09.2018).

13. Методические материалы для органов власти субъектов РФ о реализации проектов на основе государственночастного партнерства по развитию спортивной инфраструктуры. Министерство спорта РФ [Электронный pecypc]. - Режим доступа: http://www.minsport.gov. ru/2017/doc/A5_Sport_2_2017_e_.pdf (дата обращения: 05.09.2018).

14. Министерство спорта РФ. Аналитические материалы и базы данных [Электронный ресурс]. - Режим доступа: http://www.minsport.gov.ru/2017 (дата обращения: 30.09 .2018$)$.

15. Национальный центр ГЧП. Платформа поддержки инфраструктурных проектов [Электронный ресурс]. Режим доступа: http://www.pppi.ru/content/proektnyeiniciativy-0 (дата обращения: 10.09.2018).

16. Партнерство государства и частных инвесторов: методики и практика Министерства спорта России [Электронный peсурс]. - Режим доступа: http:// sportengineering.ru/article/partnerstvo-gosudarstva-ichastnyh-investorov-metodiki-i-praktika-ministerstvasporta-rossii (дата обращения: 13.09.2018).

17. План деятельности Минспорта на 2013-2018 гг. Министерство спорта РФ [Электронный ресурс]. - Режим доступа: http://www.minsport.gov.ru/ plandeiatelnstiMinsporta13-18 (дата обращения: 27.09.2018).

18. Региональный ГЧП стандарт 2.0 [Электронный ресурс]. - Режим доступа: http://www.pppcenter.ru/12reg_GCHP_standart_2-0.pdf (дата обращения: 10.09.2018).

19. Социально-экономическое положение России, январь-май, 2018 Федеральная служба государственной статистики [Электронный ресурс]. - Режим доступа: http://www.gks.ru/free_doc/doc_2018/social/osn-052018.pdf (дата обращения: 27.09.2018). kul'tury i sporta. Avtoref. dissertatsii kand. ekon. nauk [Conceptual approaches to the development of business strategy in the field of physical culture and sport. Abstract. thesis Cand. Econ. sciences]. Ekaterinburg, 2013. 24 p.

9. Sazanov V. E. Gosudarstvenno-chastnoe partnerstvo. Grazhdansko-pravovye, administrativno- pravovye i finansovo-pravovye aspekty. Monografiya [Public-private partnership. Civil, administrative, legal and financial aspects]. Moscow, «Buki Vedi», 2012. 492 p.

10. Selivanenko A. E. Predprinimatel'skaya deyatel'nost' v sfere fizicheskoi kul'tury i sporta i mekhanizm ee razvitiya v rynochnykh usloviyakh khozyaistvovaniya. Avtoref. dissertatsii kand. ekon. nauk [Business activity in the sphere of physical culture and sports and its development in market conditions. Abstract. thesis Cand. Econ. sciences diss]. Moscow, 2003. 24 p.

11. Silvestrov S. N., Kuznetsov N. I. , Podvoiskii G. L., Kotova N. E. Modeli finansirovaniya estestvennykh monopolii: byudzhetnoe, korporativnoe i proektnoe finansirovanie [Models of financing of natural monopolies: budget, corporate and project financing]. Finansy: teoriya i praktika [Finance: theory and practice], 2017, I. 5, pp. 22-29.

12. Zasedanie rabochei gruppy po voprosu razvitiya $\mathrm{GChPv}$ sfere fizicheskoi kul'tury i sporta, sozdannoi po initsiative vitse-prem'era A. Dvorkovicha (ot 29.07.2016) [Meeting of the working group on the development of PPP in the field of physical culture and sports, established on the initiative of Deputy Prime Minister A. Dvorkovich] . Available at: http://pppcenter.ru/29/ novosti/pppcenter-news/investoram-v-proektax-gchp-v-sporte-trebuetsya-garantiya-vozvratnosti-investiczij. html (accessed 10.09.2018).

13. Metodicheskie materialy dlya organov vlasti sub"ektov RF o realizatsii proektov na osnove gosudarstvenno-chastnogo partnerstva po razvitiyu sportivnoi infrastruktury. Ministerstvo sporta RF [Methodological materials for the authorities of the RF on the implementation of projects on the basis of public-private partnership for the development of sports infrastructure. Ministry of sports of the $R F]$. Available at: http://www.minsport.gov. ru/2017/doc/A5_Sport_2_2017_e_.pdf(accessed 05.09.2018).

14. Ministerstvo sporta RF. Analiticheskie materialy i bazy dannykh [Ministry of sports of the Russian Federation. Analytical materials and databases]. Available at: http://www.minsport. gov.ru/2017 (accessed 30.09.2018).

15. Natsional'nyi tsentr GChP. Platforma podderzhki infrastrukturnykh proektov [The national PPP center. Platform support for infrastructure projects]. Available at: http://www.pppi.ru/ content/proektnye-iniciativy-0 (accessed 10.09.2018).

16. Partnerstvo gosudarstva i chastnykh investorov: metodiki i praktika Ministerstva sporta Rossii [Partnership of the state and private investors: methods and practice of the Ministry of sports of Russia]. Available at: http://sportengineering.ru/ article/partnerstvo-gosudarstva-i-chastnyh-investorovmetodiki-i-praktika-ministerstva-sporta-rossii date of application 13.11.2018 (accessed 14.09.2018).

17. Plan deyatel'nosti Minsporta na 2013-2018 gg. Ministerstvo sporta RF [Plan activities Min of sport for 2013-2018, the Ministry of sport of the RF]. Available at: http://www.minsport. gov.ru/plandeiatelnstiMinsporta13-18 (accessed 27.09.2018).

18. Regional'nyi GCHP standart 2.0 [Regional PPP standard 2.0]. Available at: http://www.pppcenter.ru/12-reg GCHP_standart_2-0.pdf (accessed 10.09.2018).

19. Sotsial'no-ekonomicheskoe polozhenie Rossii, yanvar'-mai, 2018 Federal'naya sluzhba gosudarstvennoi statistiki [Socioeconomic situation in Russia, January-may, 2018 Federal state statistics service]. Available at: http://www.gks.ru/free_doc/ doc_2018/social/osn-05-2018.pdf (accessed 27.09.2018). 